\title{
SANTOS FERNÁNDEZ SANTOS (1860-1935), FOTÓGRAFO DEL PATRIMONIO RIOJANO
}

\author{
Juan Castroviejo Sanz \\ Universidad de La Rioja \\ juancastroviejo10@hotmail.com
}

\begin{abstract}
RESUMEN: Los archivos fotográficos son documentos fundamentales para el estudio de una sociedad y su entorno geográfico, económico y cultural. Detrás de estas fotografías se encuentra la figura de un fotógrafo que, en ocasiones, se dedica de manera profesional a ello y que, en otras, lo hace como aficionado. El segundo es el caso de Santos Fernández Santos, un vallisoletano que ejerció la profesión de notario en San Millán de la Cogolla entre 1887 y 1909, ocupación que compatibilizó con su gran afición a la fotografía. En este trabajo se pone de relieve la producción fotográfica de este aficionado durante su estancia en La Rioja, hasta ahora desconocida, con especial atención al patrimonio histórico-artístico. Asimismo, se destaca la importancia de este tipo de archivos fotográficos para el estudio de la documentación, la difusión y la conservación de las obras de arte capturadas.
\end{abstract}

Palabras clave: Fotografía, patrimonio histórico-artístico, Santos Fernández Santos, La Rioja, Somalo, San Millán de la Cogolla.

\section{SANTOS FERNÁNDEZ SANTOS (1860-1935), RIOJAN HERITAGE PHOTOGRAPHER}

\begin{abstract}
The photographic files are fundamental documents to the research of a society and their geographical, economic and cultural setting. Behind of these photographies we find a type of photographer that, occasionally, works in a professional way and, other times, as amateur. Santos Fernández Santos, a man who was born in Valladolid and worked as a public notary in San Millán de la Cogolla between 1887 and 1907, belongs to the second group. He juggled his job with his favourite fondness, photography. This project shows the enthusiast's picture collection during his stay in La Rioja, hitherto unknown, focused in the historical and artistic heritage. Additionally, it stresses the
\end{abstract}


importance of this type of photographic files to the evolution and work of art preservation research.

Keywords: Photography, historical-artistic heritage, Santos Fernández Santos, La Rioja, Somalo, San Millán de la Cogolla.

Recibido: 5 de Septiembre de 2016

Aceptado: 28 de Octubre de 2016

\section{Introducción}

La presentación pública del daguerrotipo en junio de 1839 en París supuso una revolución tanto a nivel artístico y comunicativo como a nivel social y económico ${ }^{1}$. Tanto es así que la difusión de este nuevo invento, primer método fotográfico de la historia, no se hizo esperar llegando a España gracias a un amplio contingente de fotógrafos extranjeros, esencialmente franceses, y llamando la atención de numerosas personalidades que se acercaron a la fotografía desde dos perspectivas diferentes. Algunos encontraron en ella su modo de vida y buscaron obtener la mayor rentabilidad de su trabajo, los Ilamados fotógrafos profesionales. Otros acudieron a ella como una afición por mero entretenimiento o con un claro interés artístico y técnico terminando, en algunos casos, insertos dentro del primer grupo o disputándoles la clientela de manera desleal ${ }^{2}$. Sin embargo, tanto los fotógrafos profesionales como los aficionados realizaron desde la segunda mitad del siglo XIX y de manera más o menos consciente una labor fundamental desde el punto de vista artístico y documental.

Además de los gabinetes y estudios donde se retrataron las grandes familias y personajes ilustres de la época, destacando por encima del resto el caso del francés Jean Laurent ${ }^{3}$, profesionales y aficionados sacaron sus bártulos a la calle cap-

1. Para conocer de manera detallada los orígenes y la evolución de la fotografía a lo largo del tiempo consultar la obra SOUGEZ, Marie Loup (coord.), Historia general de la fotografía. Madrid, Manuales Arte Cátedra, 2007. Para el caso concreto de la fotografía en España sobre sale el trabajo de LÓPEZ MONDÉJAR, Publio, Historia de la fotografía en España: fotografía y sociedad, desde sus orígenes hasta el siglo XXI. Barcelona, Lunwerg, 2005.

2. Esta guerra por la competencia llevó a los fotógrafos profesionales españoles a la cele bración en 1905 de una asamblea con el fin de organizarse frente a los fotógrafos amateurs que, en la mayoría de los casos, no cumplían sus obligaciones contributivas. Así se relata en SÁN CHEZ VIGIL, Juan Miguel (coord.), La fotografía en España: de los orígenes al siglo XXI. Madrid, Espasa Calpe, 2001, p. 197.

3. Para conocer el paso de Jean Laurent por La Rioja consultar la obra GIL DíEZ USANDI ZAGA, Ignacio (ed.), Las fotografías de J. Laurent (1816-1886) y La Rioja. Logroño, Instituto de Estudios Riojanos, 2009. 
turando aquellos aspectos más Ilamativos y representativos de los pueblos y ciudades que iban recorriendo, en ocasiones, en largos y planificados viajes como los realizados por el inglés Charles Clifford por numerosas localidades de España, incluida la ciudad de Logroño ${ }^{4}$. Los hermosos paisajes y los monumentos y obras artísticas más grandiosas, relevantes y representativas se convirtieron en los principales protagonistas en las imágenes capturadas por estos fotógrafos. Además de con fines lucrativos, puesto que las series de fotografías y postales de monumentos y vistas tuvieron una gran acogida por parte del público, esta fotografía centrada en el patrimonio natural y, especialmente, en el artístico y monumental se vio favorecida por tratarse de un instrumento fundamental para su difusión tanto a nivel regional como nacional. En el caso concreto de La Rioja, uno de los retratistas profesionales más importantes en el cambio de siglo, Alberto Muro ${ }^{5}$, generó un importantísimo archivo del patrimonio artístico riojano con fines divulgativos y propagandísticos. Por su parte, desde el plano aficionado y en la misma época, el notario Santos Fernández Santos se erigió como una figura fundamental en la documentación y difusión del patrimonio, esencialmente religioso, del entorno de San Millán de la Cogolla y el resto del valle del Najerilla.

Este trabajo se propone sacar a la luz algunas de estas fotografías tomadas en tierras riojanas por parte del notario vallisoletano en las que el patrimonio monumental y artístico, dejando a un lado el de carácter natural que en muchas de ellas se configura como un elemento compositivo imprescindible, toma un claro protagonismo. Asimismo, se destaca la importancia de dichas fotografías como documentos fundamentales en el estudio de la difusión, la evolución y la conservación de los monumentos y obras de arte, enfatizando en la necesidad de continuar con la recuperación y la inclusión de este tipo de materiales dentro del patrimonio cultural de La Rioja.

\section{Santos Fernández Santos, un notario entre La Rioja y Granada}

Santos Fernández Santos ${ }^{6}$ nació el 1 de noviembre de 1860 en Valladolid (fig. 1), como así consta en el padrón municipal de San Millán de la Cogolla del año $1889^{7}$. Se desconocen los avatares de su infancia hasta que de nuevo aparece en la documentación el 20 de junio de 1881, fecha en la que obtuvo la

4. Antonio Comi realiza algunas consideraciones acerca del paso de Clifford por la capital riojana en GIL DÍEZ USANDIZAGA, Ignacio (ed.), Las fotografías de J. Laurent..., pp. 3235.

5. ROCANDIO, Jesús (coord.), Alberto Muro. Fotografías (1895-1935). Logroño, Ayunta miento de Logroño y Casa de la Imagen, 2010.

6. En algunos documentos alusivos a su persona también aparece como Santos Fernández y Santos o Santos Fernández de Santos.

7. Archivo Municipal San Millán de la Cogolla (en adelante AMSM), Registros, Padrón muni cipal de habitantes (1889), 66/4, fol. 14 v. 
licenciatura en Derecho Civil y Canónico por la Universidad de Valladolid ${ }^{8}$. Posteriormente, entre 1882 y 1883 completó dichos estudios en la Universidad Central de Madrid al matricularse en cuatro asignaturas, a saber: Filosofía del Derecho, Derecho internacional público, Historia general del Derecho e Historia eclesiástica ${ }^{9}$. Uno de sus primeros trabajos como notario, si no el primero, le hizo recaer en La Rioja, más concretamente en San Millán de la Cogolla. Siguiendo el censo general de personas residentes en dicha localidad a fecha de 1 de marzo de 1888, la llegada de Santos Fernández Santos debió producirse hacia el mes de abril del año anterior puesto que son once los meses de residencia que se

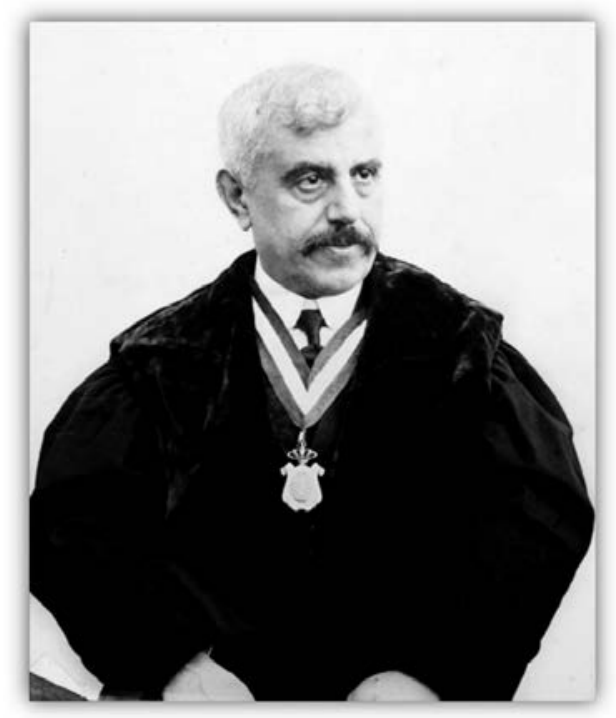

Figura 1. Anónimo, Retrato de ¿Santos Fernández [y] Santos? (Museo de La Rioja, Logroño). especifican en este documento estadístico ${ }^{10}$.

Durante estos primeros meses el nuevo notario del valle de San Millán, ya que su trabajo no se limitó a la localidad conocida por sus monasterios sino que incluyó muchos más municipios del entorno y del territorio bañado por las aguas del río Najerilla, estableció su residencia en la calle Escribanía. Sin embargo, no tardó demasiado en encontrar a la mujer con la que compartió el resto de sus días. Tal fue la prontitud que el 20 de diciembre de 1888 Santos Fernández Santos contrajo matrimonio en la propia localidad serrana con Paula Lerena Aransay $^{11}$, nacida el 5 de mayo de 1868 en el municipio cercano de Estollo ${ }^{12}$. Hija del farmacéutico Julián Lerena Bustillo, se trasladó tempranamente a San Millán de la Cogolla junto a su padre y su hermana, viviendo con algunos de sus tíos en una vivienda situada en la calle Mayor. El propio Santos Fernández se unió a la cédula familiar de los Lerena Bustillo al desposarse con Paula aunque, posterior-

8. Archivo Histórico Nacional (en adelante AHN), Universidades, Certificación académica personal, 3993, Exp. 17, fol. 18.

9. AHN, Universidades, Expediente del alumno Fernández y Santos, Exp. 17, fol. 1.

10. AMSM, Registros, Censo general de personas residentes según las cédulas de inscrip ción vecinal (1888), 62/14, fol. 5 r.

11. Archivo Parroquial Monasterio de San Millán de la Cogolla (en adelante APSM), Libro IV (Matrimonios, San Millán), fol. 84 r.

12. APSM, Libro IV (Bautizados, Estollo), fol. 48 r. y AMSM, Registros, Padrón municipal de habitantes (1889), 66/4, fol. 14 v. y 15 r. 
mente, cambiaron su residencia a la popularmente conocida como "Casa de los Notarios", situada en la misma calle Mayor y actualmente desaparecida ${ }^{13}$.

Fruto de este matrimonio nacieron entre 1889 y 1909 un total de trece hijos, siete mujeres y seis varones, todos ellos en el propio municipio de San Millán de la Cogolla ${ }^{14}$. De entre todos los hijos del matrimonio Fernández-Lerena, algunos de los cuales no alcanzaron la edad adulta, sólo se conoce el modo de vida de siete de ellos. En primer lugar, el tercero de sus hijos, Julián, siguió los pasos dados por su padre en el ámbito del Derecho dedicándose a la abogacía ${ }^{15}$. Por su parte, José hizo lo propio respecto a su abuelo materno, convirtiéndose en farmacéutico ${ }^{16}$. A la vida religiosa se entregaron tres de sus hijas, como así consta en la necrológica de Santos Fernández Santos publicada en el diario católico Siglo Futuro $^{17}$, y Manuel, que alcanzó el cargo de Capellán del Real Monasterio de la Encarnación en Madrid ${ }^{18}$. Este hecho provocó que fuera él quien asistiera al Obispo de Tabbora, Lino Rodrigo Ruesca, durante el enlace entre una de sus hermanas, $M^{\mathrm{a}}$ Natividad, y el farmacéutico de Béjar José Agero Teixidor en la Capilla del palacio Arzobispal de Granada el 6 de enero de $1933^{19}$.

Respecto al desarrollo de su ocupación profesional, Santos Fernández Santos ejerció como notario del valle de San Millán de la Cogolla un total de veintidós años, desde su llegada a la localidad homónima en el mes de abril de 1887 hasta el 4 de abril de 1909. Fue en esta última fecha cuando se suprimió de manera definitiva la notaría de San Millán de la Cogolla como consecuencia de haberse declarado excedente por parte de la Demarcación Notarial el 8 de agosto de 1907, como así figura en el protocolo de cierre custodiado en el Archivo Histórico Provincial de La Rioja ${ }^{20}$. Esta situación forzó a Santos Fernández Santos a buscar un nuevo destino para ejercer su profesión de notario, destino que encontró en tierras andaluzas, a una distancia bastante considerable del que por entonces era su hogar. Fue Granada la ciudad en la que continuó desarrollando

13. La falta de acuerdo entre las diferentes partes en lo relativo a su venta y administración provocó el derribo del inmueble tras haber sido declarado en ruina.

14. Jacinta, nacida el 20 de octubre de 1889 (APSM, Bautizados XI, fol. 129 r.); Cayetana Juliana, el 9 de febrero de 1892; Julián, el 28 de junio de 1893; Ma Rosario, el 9 de octubre de 1894; Manuel, el 23 de diciembre de 1895; José, el 24 de marzo de 1897; Casilda, el 9 de abril de 1898; Jesusa, el 2 de enero de 1900; Isabel, el 11 de julio de 1901; Ma Natividad, el 6 de septiembre de 1904; Miguel, el 17 de abril de 1906; Millán, el 13 de noviembre de 1907 (APSM, Bautizados XII, fol. 10 r., 18 r., 35 v., 43 v., 52 r., 58 v., 74 v., 92 v., 120 v., 138 v., 168 v.); y Luis Miguel, el 6 de abril de 1909 (APSM, Bautizados XIII, fol. 9 r.).

15. ABC, 23 de marzo de 1955, p. 40.

16. AMSM, Registros, Censo de población (1920), 62/17, s.f.

17. El Siglo Futuro, 8 de marzo de 1935, nº 8.467, p. 4.

18. $A B C, 23$ de marzo de 1955, p. 40.

19. El Siglo Futuro, 12 de enero de 1933, n 7.802 , p. 4.

20. Archivo Histórico Provincial de La Rioja (en adelante AHPLR), Protocolos (1909), p 9446. 
su trabajo como notario, y probablemente también como abogado, hasta la fecha de su muerte, a la edad de 74 años, el 22 de febrero de 1935. Su fallecimiento se debió a una enfermedad que se desconoce pero que únicamente le hizo pasar un día en cama y, según lo estipulado por él en su testamento, fue amortajado con el hábito de San Francisco.

Como indica la necrológica publicada en El Siglo Futuro, Santos Fernández Santos ejerció su profesión con escrupulosidad y honradez, fue un ferviente católico y militó en las filas de la Tradición, Ilegando a presidir las Juntas Tradicionalistas de Granada ${ }^{21}$. Además, tanto en esta necrológica como en el apartado "Ecos de Sociedad" referido a la ceremonia nupcial de su hija $\mathrm{M}^{\mathrm{a}}$ Natividad Fernández Lerena se observan detalles que permiten pensar en el alto poder adquisitivo y el elevando rango social de su persona y, con ello, de su familia ${ }^{22}$. Algunos ejemplos de ello son la existencia de una capilla u oratorio privado en su residencia, el amplio y granado cortejo fúnebre que acompañó a su cadáver, o la celebración de la boda de su hija en la Capilla del Palacio Arzobispal de Granada y del convite en un hotel situado en la Alhambra. Finalmente, cabe destacar que, gracias a sus amplios conocimientos en Derecho, Santos Fernández Santos colaboró y escribió artículos en revistas y publicaciones como la revista granadina La Tribuna Forense para la que redactó el trabajo "Capacidad de la mujer casada mayor de Edad"23.

A pesar del traslado de Santos Fernández Santos a Granada por motivos de trabajo, parte de su familia, especialmente su mujer y alguno de sus hijos, siguieron empadronados en San Millán de la Cogolla como consecuencia de residir en la localidad riojana de manera intermitente o, siguiendo la denominación del padrón municipal, transeúnte. Así, por ejemplo, un año después de la marcha del notario oriundo de Valladolid a la ciudad andaluza, todavía permanecen en dicho documento su mujer Paula y seis de sus hijos: Jacinta, Manuel, José, Casilda, Jesusa y Natividad ${ }^{24}$. Diez años después, en 1920, sólo Paula, Jacinta y José, que probablemente ejerció de farmacéutico en el propio municipio de San Millán, siguieron censados allín 25 .

\section{Fotógrafo del patrimonio riojano}

Santos Fernández Santos fue notario de profesión, oficio que puso en práctica durante cincuenta años hasta sus últimos días de vida. En paralelo, una de sus grandes pasiones fue la fotografía, una actividad que por no ser ni su prin-

21. El Siglo Futuro, 8 de marzo de $1935, n^{\circ} 8.467$, p. 4.

22. El Siglo Futuro, 12 de enero de 1933, n 7.802, p. 4.

23. La Alhambra. Revista quincenal de Artes y Letras, 15 de febrero de 1913, n 358, p. 70.

24. AMSM, Registros, Padrón municipal de habitantes (1910), 66/5, s.f.

25. AMSM, Registros, Censo de población (1920), 62/17, s.f. 
cipal ocupación ni su fuente esencial de ingresos le convirtió en un fotógrafo aficionado $^{26}$. Sin embargo, la gran producción y la exquisita calidad y belleza de muchas de sus imágenes permiten pensar en él como algo más que un fotógrafo aficionado, una figura mucho más cercana al mundo profesional.

Son desconocidos los motivos por los cuales Santos Fernández Santos se interesó de manera tan entusiasta por la fotografía, así como los medios a través de los cuales adquirió los conocimientos necesarios para desarrollar las técnicas fotográficas. No obstante, durante su época como notario en el valle de San Millán de la Cogolla, capturó innumerables imágenes de la zona y su entorno cercano, con especial atención al patrimonio monumental y paisajístico riojano. Como es evidente, todas estas fotografías fueron tomadas entre finales del siglo XIX y la primera década del siglo XX, antes de trasladarse en 1909 a Granada por motivos laborales. Por su parte, la actividad fotográfica Ilevada a cabo en la ciudad andaluza por el notario vallisoletano es de momento poco conocida, si bien existen algunas evidencias de que también continuó desarrollándola. Un ejemplo de ello lo conforman una serie de fotografías tomadas en Sierra Nevada, conjuntamente con el pintor Paul Sollman, que sirvieron para ilustrar una obra divulgativa de Bernaldo de Quirós publicada en 1923 por parte de la Comisaría Regia de Turismo y Cultura Artística titulada Sierra Nevada y basada en recuerdos de una excursión realizada por el propio autor en $1914^{27}$.

Entrando de Ileno en la producción fotográfica de Santos Fernández Santos en La Rioja, la mayor parte de las imágenes conocidas fueron tomadas en San Millán de la Cogolla y en los municipios cercanos situados a ambos lados del río Cárdenas: Estollo, Berceo y Badarán. Asimismo, se conoce un número importante de fotografías capturadas en localidades bañadas por el río Najerilla y caracterizadas por su riqueza monumental religiosa como son Nájera y Anguiano. Un caso aparte lo constituye el encargo realizado en la Hacienda de Somalo, cercana al municipio de Uruñuela y situada entre las aguas del propio río Najerilla y uno de sus tributarios, el río Yalde. En definitiva, si bien dominan las fotografías realizadas en el entorno de San Millán de la Cogolla, el territorio por el que este notario cargó con sus bártulos fotográficos para tomar instantáneas se extendió por gran parte del valle del río Najerilla.

26. No fueron sólo los fotógrafos profesionales los encargados de difundir y desarrollar la fotografía desde un punto de vista técnico, artístico o documental. Aquellos que, movidos por su interés artístico e incluso científico y experimental, compaginaron la fotografía con su ocu pación "oficial" a los que se ha llamado aficionados también jugaron un papel esencial en el devenir histórico de la fotografía, dejando en ocasiones obras de gran relevancia.

27. "Luces de Sulayr, Cinco siglos en la imagen de Sierra Nevada" (Junta de Andalucía): http://www.juntadeandalucia.es/culturaydeporte/ba/bivian/media/lucesdesulayr/ (Consulta: 13/9/2016). 
En todas ellas puso el acento en el patrimonio monumental y artístico, especialmente el de carácter religioso, así como en los bellos paisajes de la región, concibiendo los elementos de la naturaleza como instrumentos indispensables para la composición de sus fotografías. Otra de las características esenciales de su fotografía, que también contribuyó a crear un estilo propio bien definido, fue la introducción deliberada y anónima de personas, concediéndole a sus imágenes un cierto aspecto pictórico. En este sentido, es recurrente en sus fotografías la presencia de niños y jóvenes que aportan vida y amabilidad a la imagen ${ }^{28}$. Asimismo, Santos Fernández Santos demostró una gran atracción hacia el patrimonio monumental y artístico de La Rioja, atracción que trasladó a sus fotografías de manera constante retratando las obras más representativas de los lugares que visitó con su cámara. De esta manera, predominan entre sus capturas las de iglesias, monasterios, retablos, coros e imágenes religiosas. En definitiva, Santos Fernández Santos se sirvió de su afición por la fotografía para evidenciar su predilección por el patrimonio artístico y paisajístico riojano, patrimonio que quedó inmortalizado por su cámara generando un archivo fotográfico de indiscutible valor artístico y documental que merece ser conocido e integrado dentro del patrimonio cultural de La Rioja.

Son diversas las fuentes en las que se han localizado fotografías realizadas por Santos Fernández Santos. Sin embargo, el punto de partida lo constituyó una serie de fotografías digitalizadas en el Archivo Histórico Provincial de La Rioja que forman parte de un álbum procedente de la Hacienda de Somalo conservado en el Archivo Inspectorial Salesiano, muchas de las cuales se atribuyeron al notario vallisoletano. A partir de este primer descubrimiento fueron localizándose otros muchos ejemplos de su trabajo fotográfico en fondos como el del Museo de La Rioja y de asociaciones culturales como los Amigos de la Historia Najerillense, en publicaciones de carácter artístico y erudito, en la prensa riojana de principios del siglo XX e incluso en colecciones privadas. Todas estas fotografías permiten acercarse a la figura de Santos Fernández Santos desde el punto de vista de su producción fotográfica aficionada, dejando patente la relevancia artística y documental de su obra, así como su importancia desde el ámbito del patrimonio cultural. Asimismo, resulta razonable pensar que este conjunto gráfico localizado es sólo una pequeña parte de toda su obra fotográfica y que, por lo tanto, resta todavía una gran labor de investigación acerca de su figura y de recuperación de sus fotografías.

Entrando en el análisis de cada una de estas fuentes, como se ha comentado con anterioridad, fue el Ilamado "Álbum de Somalo" el punto de partida en la

28. Resulta bastante probable que estos niños y jóvenes que aparecen de manera recurrente en sus fotografías, se correspondan con alguno de sus hijos, quienes pudieron acompañar a Santos Fernández Santos en sus salidas y paseos con el objetivo de tomar imágenes con su cámara. 
realización de este trabajo. Pese a estar de manera física en propiedad de la Congregación Salesiana, las fotografías alojadas en dicho álbum fueron conocidas a través de una digitalización de las mismas por parte del Archivo Histórico Provincial de La Rioja. Exceptuando cinco de estas imágenes, el resto forma parte de un reportaje llevado a cabo por el notario y fotógrafo vallisoletano atendiendo al encargo de uno de los propietarios de la Hacienda de Somalo, Eduardo Sáenz de Santander. Asimismo, es necesario señalar que entre los fondos de la Asociación Amigos de la Historia Najerillense se conservan diecinueve negativos en cristal pertenecientes a tal encargo, coincidiendo gran parte de ellos con las fotografías positivadas en el "Álbum de Somalo".

La Hacienda de Somalo se localiza en la Comunidad Autónoma de La Rioja, enclavada entre los términos municipales de Uruñuela y Torremontalbo, a oriIlas de los ríos Najerilla y Yalde. La primera alusión a estas tierras aparece en diciembre de 1052 en la Carta fundacional del Monasterio de Santa María la Real de Nájera redactada por el rey García III "el de Nájera"29. En este documento se enumeran las diferentes posesiones que el monarca concede al recién fundado monasterio, posesiones entre las cuales se incluyen "las villas que se Ilaman Sotomalo" ${ }^{\prime 30}$, en clara referencia a las tierras que, con probables variaciones, configurarían posteriormente la Hacienda de Somalo. Estas donaciones fueron ratificadas por los sucesivos monarcas, manteniéndose Somalo en manos del Monasterio de Santa María la Real de Nájera hasta los procesos desamortizadores de 1820 y, con mayor efectividad, el decretado por Mendizábal en febrero de 1836. Siguiendo lo defendido por Santos Sastre en base a documentos procedentes de esta hacienda conservados en el Archivo Inspectorial Salesiano, León García Villarreal adquirió estas tierras durante el primer proceso desamortizador de 1820. Sin embargo, es probable que tuviera que devolverlas con posterioridad para acabar adquiriéndolas de forma definitiva en el proceso desamortizador promovido por Mendizábal ${ }^{31}$. Así, en 1842 compró seis viñas y una heredad en la jurisdicción de Somalo que habían pertenecido al Monasterio de Santa María la Real de Nájera y, un año después, adquirió otras cuatro heredades también en Somalo ${ }^{32}$.

29. CANTERA MONTENEGRO, Margarita, "Santa María la Real de Nájera en la Edad Media" en DE LA IGLESIA DUARTE, José Ignacio (coord.), I Semana de Estudios Medievales, Nájera, del 6 al 11 de agosto de 1990. Logroño, Instituto de Estudios Riojanos, 2001, p. 208.

30. Traducción del documento original realizada por Santos Sastre en su obra SASTRE, San tos, Somalo..., p. 1.3.

31. Archivo Inspectorial Salesiano (en adelante AIS), Edificios existentes en Somalo en 1823, 65002 .

32. LÁZARO TORRES, Rosa María, La desamortización de Espartero en Logroño. Logroño, Instituto de Estudios Riojanos, 1977, pp. 8384. 
Fue de este modo como León García Villarreal se convirtió en el primer propietario de la Hacienda de Somalo. Su muerte en 1866 hizo que la propiedad de Somalo fuera heredada por su hijo Eusebio y, tras el fallecimiento de éste, por su nieta Genoveva quien contrajo matrimonio en 1893 con el más que probable promotor del "Álbum de Somalo" que contiene las fotografías de Santos Fernández Santos, Eduardo Sáenz de Santander. Con la muerte de Genoveva en 1926, la propiedad de la Hacienda de Somalo pasó a sus manos y, dos años después, contrajo matrimonio en segundas nupcias con Elena Ruiz de Azcárraga. Ella fue quien heredó estas posesiones y, tras su muerte en diciembre de 1965 y en aplicación de lo estipulado en su testamento, quien las legó a la Congregación Salesiana para su gestión, como así sucede en la actualidad.

Es esta congregación religiosa la que conserva el "Álbum de Somalo", titulado en su portada "SEÑORÍO DE SOMÁLO". Contiene un total de cincuenta y tres fotografías de las cuales cuarenta y ocho se atribuyen al fotógrafo Santos Fernández Santos. La autoría de las cinco restantes se desconoce, siendo todas ellas retratos de miembros de la familia propietaria de la Hacienda. Dejando a un lado estas fotografías de autoría anónima, las imágenes capturadas por Santos Fernández Santos respondieron a un encargo de Eduardo Sáenz de Santan$\operatorname{der}^{33}$. Fue una de las pequeñas descripciones manuscritas que éste acompañó a las imágenes la que aportó la autoría de las fotografías en favor del notario vallisoletano, gracias a la aparición de una de sus hijas en una de ellas. Además, este mismo manuscrito permitió datarlas hacia 1908, año en el que el párroco Lázaro Ruiz Gamarra, que también fue retratado en la misma fotografía, actuó como administrador de la Hacienda de Somalo $^{34}$ (fig. 2).

El reportaje fotográfico realizado por Santos Fernández Santos en Somalo se orientó hacia la descripción pormenorizada de los elementos más significativos y representativos de la Hacienda, desde los edificios y estancias principales de los mismos hasta las tierras de cultivo y los rebaños, pasando por el personal de trabajo de la finca, los aperos y la maquinaria para su explotación, así como los bellos paisajes del entorno. Todo ello con la intención por parte de Eduardo Sáenz de Santander de destacar su distinguida posición social a través de las numerosas y vastas posesiones de la Hacienda de Somalo, en una clara actitud de alarde y ostentación.

Santos Fernández Santos plasmó su propio estilo fotográfico en este reportaje de la Hacienda de Somalo con maestría desde los puntos de vista estético y

33. La afirmación de que fue el propio Eduardo Sáenz de Santander el que realizó el encar go de este reportaje fotográfico se fundamenta en la recurrente y preeminente aparición de su figura en varias de las fotografías, así como en la inclusión de comentarios de su puño y letra (cotejada con documentos suyos conservados en el Archivo Histórico Provincial de La Rioja) sobre las imágenes dispuestas en el álbum.

34. AIS, Apuntes del Párroco de Uruñuela D. Luis Díaz de Cerio, 65017, p. 30 r. 


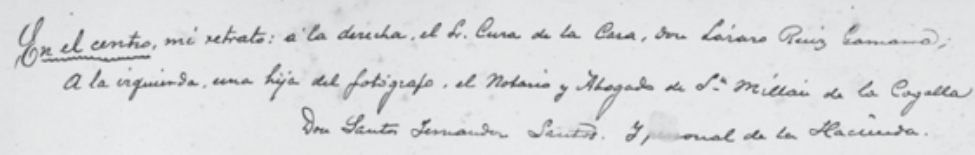

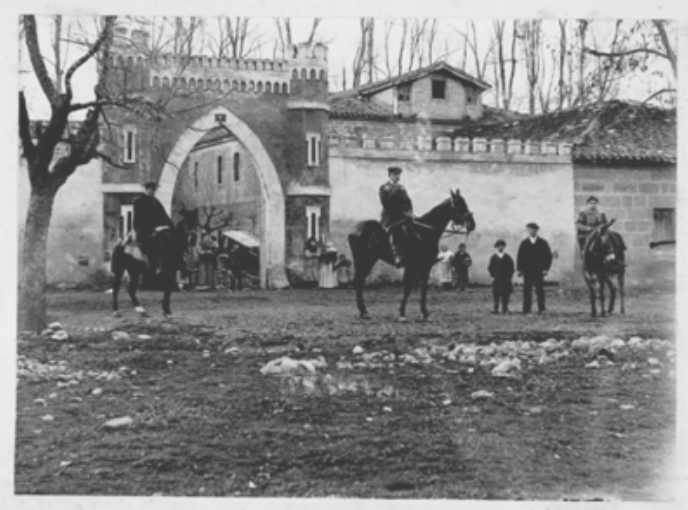

.5

Figura 2. Santos Fernández [y] Santos, Eduardo Sáenz de Santander, Lázaro Ruiz Gamarra, hija de Santos Fernández Santos y personal en la puerta de acceso a la Hacienda de Somalo, h. 1908, Álbum del Señorío de Somalo (AIS).

compositivo. En primer lugar, introdujo de manera deliberada tanto a las personas como a determinados objetos que consideró dignos de poseer un lugar preeminente en la imagen. Así, en las fotografías en las que aparecen personas la gran mayoría lo hacen posando ante la cámara del notario vallisoletano, siendo conscientes de que están siendo retratadas. En concreto, en varias de las imágenes aparece un joven ataviado con traje y boina del que se sirvió recurrentemente para romper la monotonía del paisaje y aportar un carácter amable a la composición. Por su parte, existen fotografías en las que determinados objetos se localizan en lugares poco comunes, como en el caso de uno de los gabinetes en el que un fonógrafo se exhibe frente a la puerta principal de acceso a la estancia, cubierta por amplios cortinajes (fig. 3).

En segundo lugar, utilizó la vegetación y, en este caso concreto, el arbolado de choperas y encinas de la zona para encuadrar sus fotografías, sirviéndole al mismo tiempo como elementos compositivos. Esta presencia de la naturaleza fue constante y fundamental en la obra fotográfica de Santos Fernández Santos. Tanto es así que, aprovechando el encargo realizado por Eduardo Sáenz de Santander, realizó numerosas vistas de paisajes de la Hacienda de Somalo con un fuerte carácter pictórico, incluyendo en algunas de ellas tierras de cultivo y edificios destinados a diferentes labores. Este es el caso de fotografías como la que 


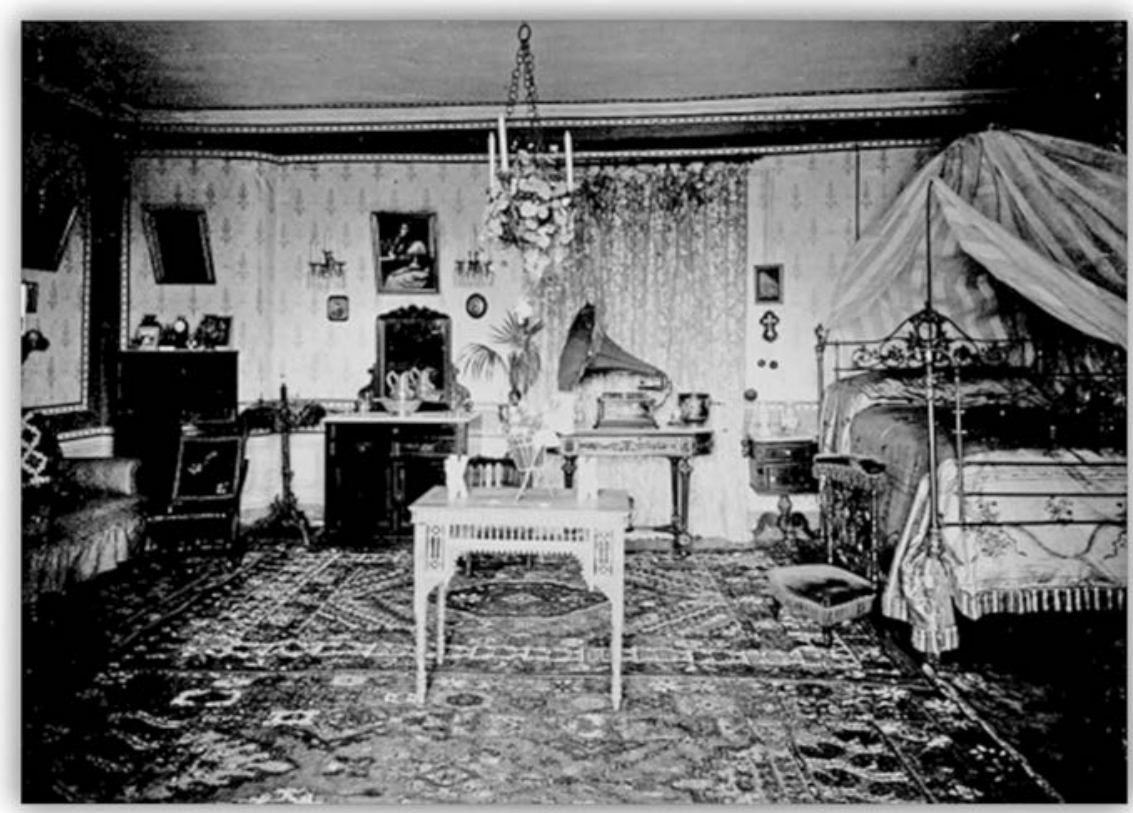

Figura 3. Santos Fernández [y] Santos, Dormitorio con fonógrafo en la vivienda de la Hacienda de Somalo, h. 1908, Álbum del Señorío de Somalo (AIS).



Figura 4. Santos Fernández [y] Santos, Paisaje de chopos en torno a una bodega, h. 1908, Álbum del Señorío de Somalo (AIS). 
presenta el paraje en el que se localiza la bodega o "Cueva" en la que una hilera de chopos envuelve al edificio (fig. 4).

Analizando cada una de las fuentes restantes en las que se localizan fotografías de Santos Fernández Santos resulta interesante comenzar hablando de los fondos conservados en el Museo de La Rioja. La entrada de estos fondos respondió a una donación realizada en el año 2006 por parte de Alejandro Rodríguez Romero $^{35}$. Su procedencia más probable parece ser la residencia que el propio notario vallisoletano ocupó durante su estancia en San Millán de la Cogolla y que popularmente se conocía como "Casa de los Notarios". Dejando a un lado algunos objetos artísticos no relacionados con la fotografía, en el registro de esta donación se incluyeron un total de 142 placas de cristal de $13 \times 18 \mathrm{~cm}, 57$ placas de cristal de $6 \times 9 \mathrm{~cm}, 2$ placas de cristal de 9x13 cm, 42 copias positivadas de $20 \times 30 \mathrm{~cm}$ y, finalmente, 4 diplomas de premios obtenidos entre 1905 y 1907.

Entre todos estos materiales fotográficos, la gran mayoría de ellos obra de Santos Fernández Santos, aparecen diversos tipos de fotografías. En primer lugar, son bastante numerosas las placas de negativos en cristal de diferentes medidas que presentan vistas y paisajes de San Millán de la Cogolla y localidades del entorno. Algunos de estos negativos se encuentran positivados aunque, en este caso, la temática es mucho más amplia. Así, además de vistas y paisajes de San Millán de la Cogolla, Badarán, Berceo, Estollo y Anguiano, aparecen varias imágenes del patrimonio monumental, destacando los monasterios de San Millán de Yuso y Suso, Nuestra Señora de Valvanera y Santa María la Real de Nájera; fotografías interiores de estos y otros templos cristianos centradas en sus retablos y coros; imágenes de Vírgenes y Niños; y reproducciones de grabados de cuadros tan relevantes como la Inmaculada Concepción de los Venerables de Bartolomé Esteban Murillo. Muchas de estas fotografías positivadas se encuentran enmarcadas sobre cartones y cartulinas que, en muchos casos, presentan una estética similar (fig. 5) y, en menor medida, tamponadas en su reverso con una pequeña carta de presentación en la que el fotógrafo y notario indicó su nombre, sus premios fotográficos y su localización (fig. 6).

Mención especial merecen un total de siete fotografías, montadas todas ellas sobre cartulinas de colores oscuros sin ningún tipo de decoración, que fueron presentadas a concursos fotográficos. Esta afirmación se sostiene en el hecho de que, además de presentar un título en la parte anterior, en la parte posterior del cartón o cartulina incluyen un número, un lema y un pseudónimo. Entre este conjunto particular de fotografías eminentemente artísticas destacan tres que

35. La Orden Ministerial del Ministerio de Cultura del 3 de octubre de 2006 aprobó la incor poración de estos materiales valorados en $4.000 €$ y donados por Alejandro Rodríguez Romero a los fondos del Museo de La Rioja, incorporación que se hizo material el 6 de octubre de 2006 bajo el número de registro 16.127 (Información proporcionada por el Museo de La Rioja). 


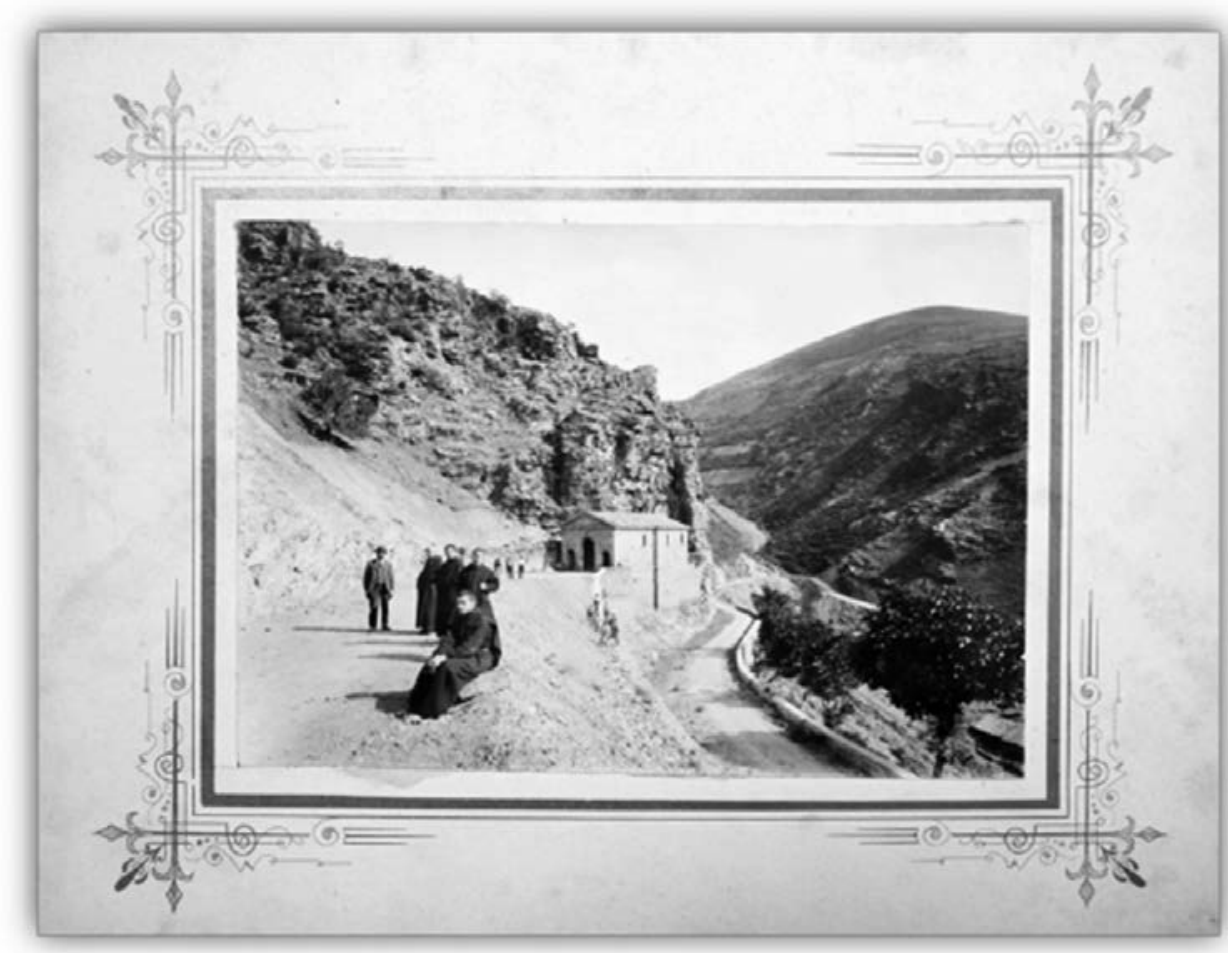

Figura 5. Santos Fernández [y] Santos, Ermita del Santo Cristo en Valvanera (Museo de La Rioja, Logroño).

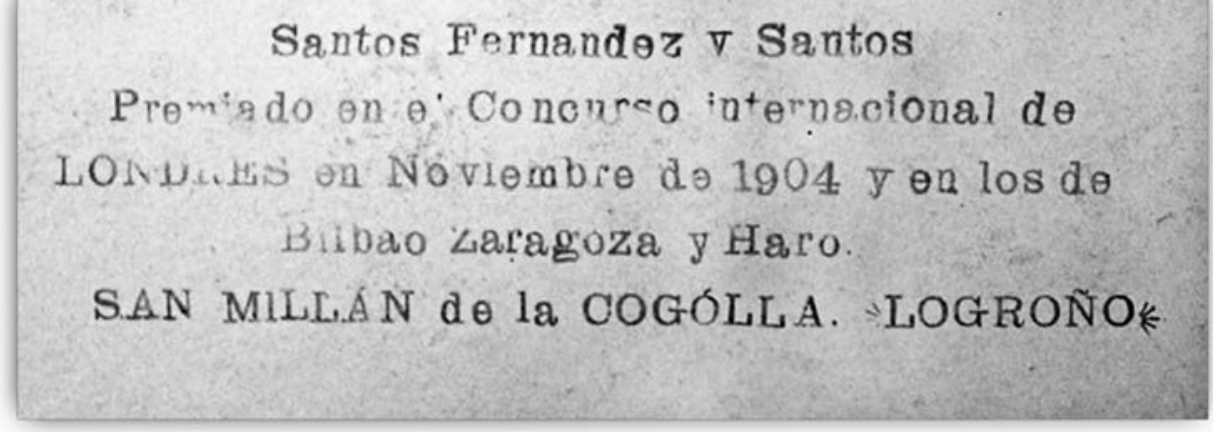

Figura 6. Detalle del tamponado incluido por Santos Fernández [y] Santos en el reverso de algunas fotografías (Museo de La Rioja, Logroño). 




Figura 7. Santos Fernández [y] Santos, Lavanderas (Museo de La Rioja, Logroño).

conforman una serie presentada a un mismo concurso, ya que presentan números correlativos en el dorso (286, 287 y 288). Presentadas bajo el lema "Baskonia" y el pseudónimo "Renem", están realizadas mediante la técnica fotográfica del carbón y tienen por protagonistas a diferentes mujeres. Dos de ellas presentan a una (Contra-luz) y dos mujeres (Lavanderas), respectivamente, lavando la ropa a orillas de un río (fig. 7). La tercera y última titulada Paisaje también gira en torno a la figura de una mujer con amplia vestimenta, aunque en este caso pasea por un bosque de ribera con un gran cesto bajo su brazo izquierdo. En el resto de fotografías presentadas a concurso aparecen una religiosa recostada en la esquina de una habitación diáfana, una mujer sesteando sobre una mesa de comedor, un bello estanque y una escena en la que unos animales de tiro sacan una barca hacia el mar.

La calidad artística y compositiva de las fotografías de Santos Fernández Santos fue premiada en varias ocasiones como lo demuestra el tamponado, anteriormente comentado, presente en algunos reversos de sus imágenes montadas sobre cartón en el que se enumeran premios obtenidos en el Concurso Internacional de Londres en noviembre de 1904 y en otros concursos de Bilbao, Haro y Zaragoza. De hecho, de este último caso se conservan en el Museo de La Rio- 
ja un total de cuatro bellos diplomas de estética modernista que especifican diferentes galardones en el concurso convocado por la revista zaragozana Photos. En concreto, en 1905 recibió la medalla de oro y una mención especial, en el concurso de 1906 fue distinguido con la medalla de bronce, mismo reconocimiento que alcanzó un año después, en septiembre de 1907.

Antes de comentar las fotografías de Santos Fernández Santos presentes en publicaciones artísticas y eruditas, es necesario señalar que también se conoce la existencia de instantáneas del notario vallisoletano en otros fondos fotográficos de diferentes instituciones como la Biblioteca Nacional y el Monasterio de Yuso en San Millán de la Cogolla. Por un lado, en la Biblioteca Nacional se conserva una fotografía del retablo de San Millán de Suso datada hacia 1900 y reproducida posteriormente en publicaciones e incluso tarjetas postales ${ }^{36}$. Por otro lado, se tiene constancia de la conservación en los fondos del Monasterio de Yuso de placas de vidrio originales de Santos Fernández Santos en las que se reproducen ambos edificios monásticos de Suso y Yuso, otros edificios colegiales como el Colegio Reparatorio de la Orden de Padres Agustinos Recoletos y retratos de habitantes de la propia localidad de San Millán de la Cogolla.

Varias fueron las publicaciones que se sirvieron de las fotografías tomadas por Santos Fernández Santos para ilustrar sus textos y artículos eruditos relacionados, en la mayor parte de los casos, con el patrimonio artístico y monumental riojano de carácter religioso. Dos de ellas acudieron a las imágenes tomadas por el notario nacido en Valladolid de los relieves en marfil del Arca de San Millán y del Arca de San Felices, ambas custodiadas en el Monasterio de Yuso. La primera en realizarlo fue la Sociedad Española de Excursiones que en su Boletín del 1 de marzo de 1908 incluyó un artículo divulgativo de carácter histórico-artístico firmado por Narciso Setenach titulado "Relieves en marfil del arca de San Millán de la Cogolla", pudiendo llevar a cierta equivocación pues gira en torno a las placas de marfil que configuran ambas arcas, y no sólo la de San Millán ${ }^{37}$. En la presentación del artículo, Setenach se refirió al fotógrafo como un pilar fundamental para poder llevar a cabo este trabajo con las siguientes palabras:

Con este motivo son hoy objeto de un proceso criminal, y gracias á [sic] este incidente, cómo á [sic] la pericia del excelente fotógrafo D. Santos Fernández y Santos, premiado en el Concurso internacional Luna de Londres, en Noviembre de 1904, y á [sic] la generosidad del actual ilustrísimo Obispo de Sigüenza, Fr. Toribio Minguella, que ha donado al Museo Arqueológico Nacional una colección de las fotografías, de las que reproducimos

36. Información proporcionada por el Doctor en Historia del Arte Fernando Gutiérrez Baños, a quien es necesario agradecer su colaboración.

37. SETENACH, Narciso, "Relieves en marfil del arca de San Millán de la Cogolla" en Boletín de la Sociedad Española de Excursiones, 1 de marzo de 1908, Madrid, vol. 16, pp. 415. 
tres en fototipias, nos es dado poder hacer de tan interesantes relieves el presente estudio ${ }^{38}$.

En consecuencia, a lo largo del estudio se incluyen un total de tres fototipias de Hauser y Menet que reproducen tres de las fotografías realizadas por Santos Fernández Santos a las placas de marfil del Arca de San Felices y el Arca de San Millán respectivamente: la que representa la Última Cena (fig. 8), otra en la que aparece Cristo curando a enfermos y, finalmente, una última de carácter histórico en la que se representa la predicación de San Millán en la parte superior y la destrucción de Cantabria por parte de Leovigildo en la parte inferior.

Por su parte, Cristóbal de Castro afirma lo siguiente en la presentación de su Catálogo monumental y artístico de la provincia de Logroño:

Habiéndonos denegado, con toda cortesía, pero también con toda firmeza, la contemplación de la famosa arqueta con relieves en marfil, que se guarda en el monasterio de San Millan [sic] de la Cogolla, hemos podido procurarnos las magníficas fotografías que las reproducen, adquiriéndolas de don Santos Fernández, actualmente notario en Granada, cuyo recibo obra en nuestro poder ${ }^{39}$.

De esta manera, en el segundo volumen de su obra dedicado exclusivamente al apartado gráfico de las obras y monumentos catalogados en el primero, se incluyen un total de dieciocho fotografías realizadas por Santos Fernández Santos tanto de la vista general de las dos arcas como de los propios marfiles en detalle. Asimismo, resulta necesario señalar que muchas de las fotografías que aparecen a lo largo de este segundo volumen referidas a San Millán de la Cogolla y el Monasterio de Nuestra Señora de Valvanera se tratan de copias de instantáneas realizadas también por el notario vallisoletano. Esta afirmación se basa en el hecho de que muchas de ellas coinciden con las fotografías conservadas en el Museo de La Rioja y anteriormente comentadas.

Vicente Lampérez y Romea también utilizó las imágenes tomadas por Santos Fernández Santos en los edificios monásticos de San Millán para ilustrar dos publicaciones de carácter artístico. En 1907 incluyó dos fotografías, una del vestíbulo y otra del sepulcro del Monasterio de Suso, en el capítulo titulado "La iglesia de San Millán de la Cogolla de Suso (Logroño)" perteneciente al Boletín de la Sociedad Castellana de Excursiones ${ }^{40}$. Dos años después, Lampérez y

38. Ídem, p. 6.

39. DE CASTRO, Cristóbal, Catálogo monumental y artístico de la provincia de Logroño. Logro ño, Ministerio de Instrucción Pública y Bellas Artes, 1915 1916, vol. 1, p. 15. Edición digital en: http://biblioteca.cchs.csic.es/digitalizacion tnt/index interior logrono.html (Consulta: 13/9/2016).

40. LAMPÉREZ Y ROMEA, Vicente, "La iglesia de San Millán de la Cogolla de Suso (Logro ño)", Boletín de la Sociedad Castellana de Excursiones, 1907, vol. 59, pp. 246250. 


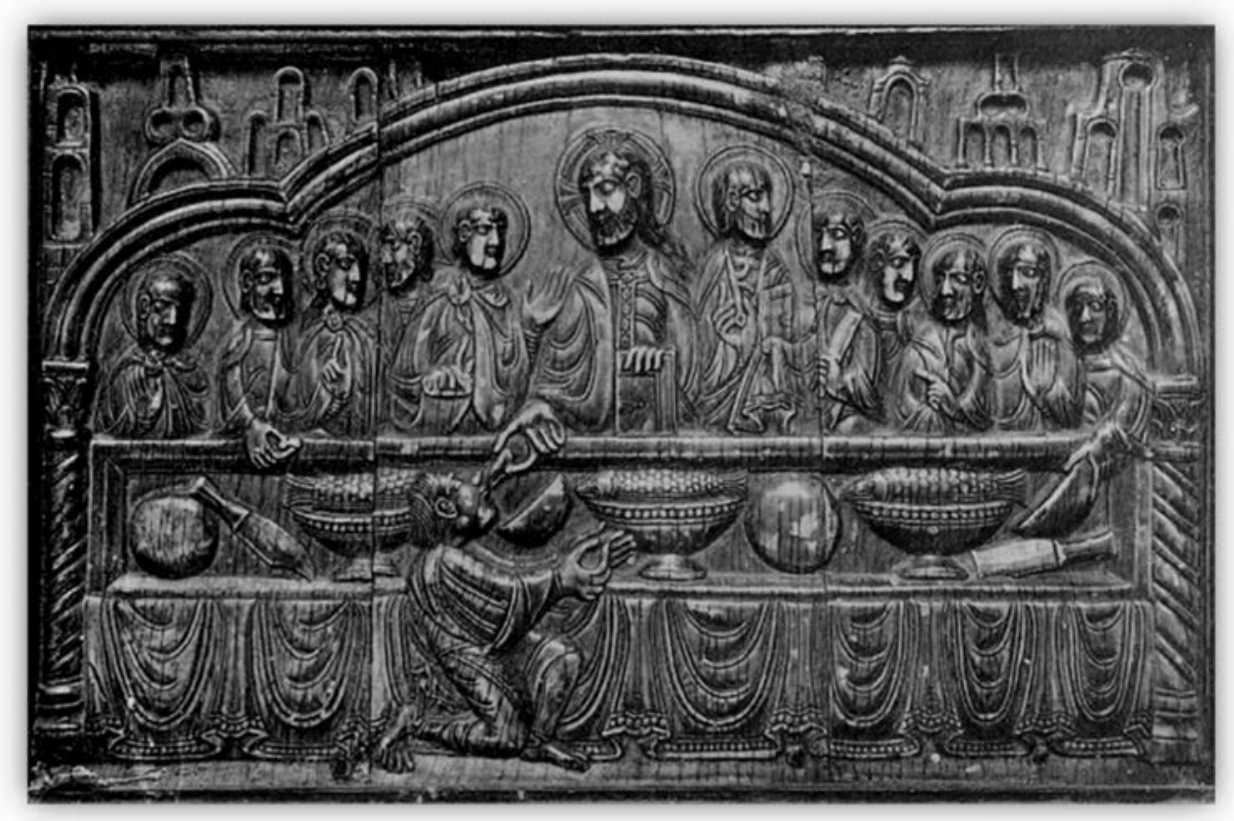

Figura 8. Santos Fernández [y] Santos, Relieve en marfil del Arca de San Felices representando la Cena del Señor, Fototipia de Hauser y Menet (BSEE, 1 de marzo de 1908, Madrid, vol. 16).

Romea escribió la obra Historia de la Arquitectura Cristiana Española en la Edad Media, según el estudio de los elementos y los monumentos, obra en la que introdujo una fotografía de los capiteles de San Millán de la Cogolla ${ }^{41}$.

La presencia del quehacer fotográfico de Santos Fernández Santos en la prensa regional y nacional estuvo de nuevo asociada a la riqueza monumental y artística de La Rioja, esencialmente en su vertiente religiosa. Por un lado se encuentra el caso de la revista semanal Rioja Ilustrada. En su decimoctavo número, publicado el 6 de mayo de 1907, tres fotografías bajo la firma de Fernández Santos ilustran un artículo de prosa erudita, como así se define en la propia revista, escrito por Luis Barbero en el que narra su visita al Monasterio de Santa María la Real de Nájera, visita en la que quedó maravillado². A este panegírico sobre el hermoso monumento najerino le acompaña una vista general del municipio, en la que domina el puente de piedra sobre el río Najerilla,

41. LAMPÉREZ Y ROMEA, Vicente., Historia de la Arquitectura Cristiana Española en la Edad Media, según el estudio de los elementos y los monumentos. Madrid Barcelona, Espasa Calpe, 1930, p. 234.

42. Rioja llustrada, 6 de mayo de 1907, no 18, p. 163. 




Figura 9. Santos Fernández [y] Santos, Claustro de los Caballeros del Monasterio de Santa María la Real de Nájera, h. 1907 (Museo de La Rioja, Logroño).

una imagen del coro alto y una última capturada desde el interior del patio del Claustro de los Caballeros (fig. 9).

Únicamente en este artículo de Rioja Ilustrada aparece la firma de Santos Fernández Santos. Sin embargo, existen motivos para pensar que en otros tres números consecutivos en los que también aparecen artículos de Luis Barbero sobre Santa María la Real de Nájera las fotografías que los ilustran, en este caso de manera anónima, pudieran ser realizadas también por el notario vallisoletano. Estos números publicados el 20 y 27 de mayo y el 3 de junio de 1907 se configuran como una ampliación del artículo introductorio anteriormente comentado describiendo cada una de las partes más características del monasterio. El primero, incluido en el vigésimo número de la revista, se centra en la Iglesia e incluye tres fotografías: una del claustro, otra de la galería izquierda del coro alto y una última desde el patio interior. El segundo, dedicado al Coro alto y el Claustro de los Caballeros, se ilustra con una instantánea de uno de los ángulos del claustro. El tercero y último, a pesar de tratar en exclusividad del Panteón, se acompaña de un total de cuatro fotografías de la Cueva de la Virgen, un detalle de la sillería del coro, una de las puertas de acceso al edificio y el propio Panteón.

Varios peldaños por encima, tanto en prestigio como en nivel de erudición, aparece la revista científica de ámbito nacional Ilamada Arte Español. En su 


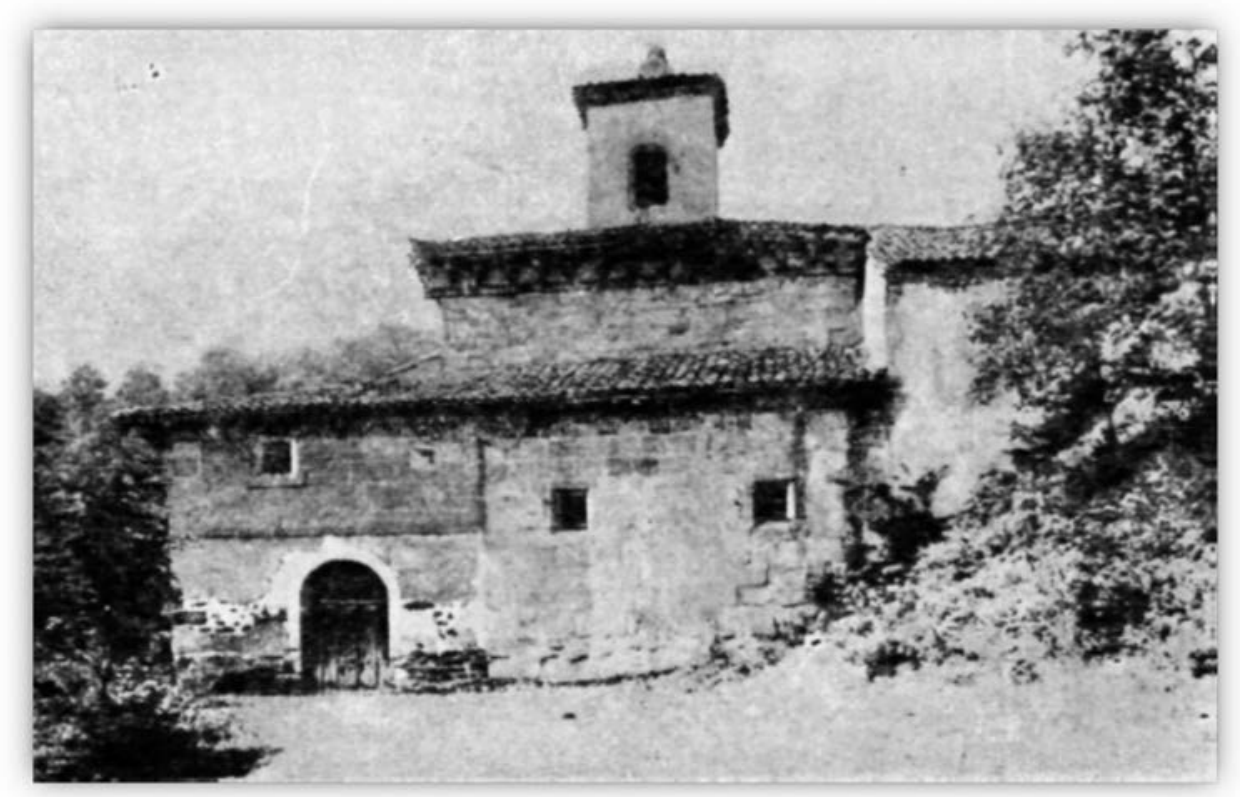

Figura 10. Santos Fernández [y] Santos, Entrada al Monasterio de Suso (Arte Español, agosto de 1915, $n^{\circ} 7$, p. 373).

número de agosto de 1915 el agustino recoleto Fray Pedro Fabo publicó un extenso artículo dedicado a San Millán de la Cogolla ${ }^{43}$. Para ilustrarlo utilizó un total de doce fotografías de Santos Fernández entre las que se incluyen: una vista de la localidad de Berceo desde el camino de Estollo, dos vistas generales del Monasterio de Yuso al que el autor considera "El Escorial de La Rioja", una imagen del claustro bajo de dicho monasterio, dos fotografías del interior de la basílica y la sacristía, un retrato colectivo de los profesores con los alumnos del colegio y otro con los jóvenes componentes de la banda de música, una vista general del Monasterio de Suso (fig. 10) y los detalles del interior, el altar mayor y el sepulcro de San Millán ${ }^{44}$.

Finalmente es necesario hacer alusión a las colecciones particulares entre las cuales se conservan fotografías realizadas por el notario vallisoletano. La fotografía, como objeto físico, es fácilmente transportable, una ventaja que en ocasiones se convierte en un inconveniente para su conservación pues hace

43. FABO, Fr. Pedro, "San Millán de la Cogolla" en Arte Español, agosto de 1915, n 7, pp. 363378.

44. Cinco de estas fotografías también aparecen en la obra FABO, Fr. Pedro, El convento de San Millán. Cádiz, Imp. Manuel Álvarez, 1914 1915, pp. 826. 
más sencillo que se extravíe entre papeles y otros objetos. Asimismo, la fotografía no ha sido valorada como se merece y, en muchas ocasiones, ha pasado de unas manos a otras alejándose de su lugar y su propietario original. Por este motivo, resulta probable que existan numerosas imágenes capturadas por Santos Fernández Santos por diferentes lugares de España, incluso fuera de ella, algo que pudo favorecerse con su traslado desde San Millán a Granada y la realización de postales con grandes tiradas a partir de sus fotografías. En el ámbito riojano una de las colecciones privadas más importantes es la de Antonio Comi, colección en la que se encuentran numerosas de estas postales anteriores a 1905 y algunas fotografías variadas procedentes de la llamada "Casa de los Notarios", también atribuidas a Santos Fernández Santos.

\section{Importancia del legado fotográfico de Santos Fernández Santos}

Toda la obra fotográfica conocida de Santos Fernández Santos realizada en el territorio riojano, y por consiguiente aquella que todavía permanece sin estudiar o en el desconocimiento, posee un valor muy importante desde diferentes ámbitos: el puramente fotográfico, el relacionado con el estudio artístico y monumental, el histórico e identitario, el documental y etnográfico y, finalmente, el puramente patrimonial.

En primer lugar, es necesario reseñar el hecho de que, hasta este momento, su figura como fotógrafo era desconocida o, en el mejor de los casos, permanecía olvidada. De hecho, la única referencia bibliográfica al quehacer fotográfico de Santos Fernández Santos en La Rioja se limitaba a la inclusión de su persona en una lista más amplia de fotógrafos cuyas imágenes fueron publicadas en prensa ${ }^{45}$, probablemente en alusión a las fotografías tomadas en el Monasterio de Santa María la Real de Nájera presentes en la revista semanal Rioja Ilustrada, comentadas con anterioridad. A esta mínima referencia habría que incluir las alusiones tanto de Narciso Setenach como de Cristóbal de Castro a las fotografías realizadas por el notario vallisoletano a los marfiles de las Arcas de San Millán y San Felices. A pesar de todo ello, resulta evidente que las imágenes capturadas por Santos Fernández Santos en el territorio riojano, con especial atención a la zona de San Millán y gran parte del valle del Najerilla, poseen una calidad y una belleza destacable desde el punto de vista meramente fotográfico. La composición, el encuadre, la colocación deliberada de elementos, la introducción de personas o la inclusión en las fotografías de los elementos más bellos e importantes de los lugares retratados así lo demuestran. Del mismo modo, el hecho de recibir numerosos premios en concursos fotográficos tanto nacionales como internacionales apoyan la afirmación de que, a pesar de ser

45. ROCANDIO, Jesús, Cien años de fotografía..., p. 32. 
un fotógrafo aficionado, sus conocimientos teóricos y técnicos le ayudaron a desarrollar una obra mucho más cercana a los ámbitos profesionales.

Esta obra fotográfica, como se ha podido comprobar, se centró en su mayor parte en el patrimonio monumental riojano de la región cercana a San Millán de la Cogolla, lugar en el que estableció su residencia por motivos de trabajo. De este modo, si bien fueron los monasterios de dicha localidad y las obras de arte que en ellos se conservaban los que dominaron desde el punto de vista cuantitativo, Santos Fernández Santos recorrió varios municipios del valle del Najerilla capturando con su cámara los lugares y monumentos más representativos de los mismos, con especial atención a las obras de carácter religioso como el Monasterio de Santa María la Real de Nájera o el Monasterio de Nuestra Señora de Valvanera. Además de permitir a los estudiosos de su época y de décadas posteriores sustentar sus trabajos con un apartado gráfico de innegable valor, como así lo demuestran por ejemplo los artículos sobre los marfiles de las Arcas de San Millán y San Felices o los descriptivos reportajes sobre los Monasterios de San Millán de la Cogolla y Nájera, se convierten en documentos fundamentales para el estudio tanto de la evolución y la conservación de las obras de arte capturadas como de los cambios acaecidos en el urbanismo de las localidades fotografiadas.

Por lo tanto, las imágenes tomadas por el notario y fotógrafo vallisoletano son esenciales para el conocimiento del estado de algunas de las obras de arte y monumentos, especialmente religiosos, más representativos en el ámbito riojano durante los últimos años de siglo XIX y la primera década del siglo XX. Tanto es así que cualquier estudio sobre los Monasterios de San Millán de Suso y Yuso, el Monasterio de Santa María la Real de Nájera, el Monasterio de Nuestra Señora de Valvanera o el propio complejo arquitectónico de la Hacienda de Somalo, entre otros, no puede obviar la consulta y el análisis minucioso de las fotografías realizadas por Santos Fernández Santos. De la misma manera, y teniendo en cuenta la importancia que el fotógrafo aficionado concedió al paisaje y el entorno natural de todos estos monumentos, sus imágenes también se presentan como fuentes primordiales para el estudio de la evolución paisajística de determinadas zonas del valle del Najerilla, concretamente de los municipios que aparecen en ellas: Anguiano, Badarán, Berceo, Estollo, Nájera, San Millán de la Cogolla o Uruñuela (Somalo).

En relación con todo ello, las fotografías del notario vallisoletano permitieron una difusión de la riqueza artística, monumental y paisajística riojana, especialmente a través de las series de postales que se realizaron a partir de ellas. En estas postales se incluyeron los monumentos, obras artísticas y paisajes más representativos de la región, sirviendo así como un elemento de propaganda turística hacia el exterior y, al mismo tiempo, como una reafirmación de la identidad, la singularidad y la belleza del territorio riojano. Es por este motivo por el que las fotografías tomadas por Santos Fernández Santos en ambos monasterios de San Millán fueron reproducidas en series de postales, remarcando su 
importancia como lugar en el que permaneció gran parte de su vida el milagroso santo del mismo nombre y donde aparecieron los primeros textos escritos en castellano.

Por otro lado, también conviene señalar el factor documental e incluso etnográfico del trabajo de Santos Fernández Santos, especialmente destacado en el reportaje de la Hacienda de Somalo. Las imágenes allí tomadas contribuyen de manera evidente a documentar históricamente esta hacienda en la primera década del siglo $X X$, realizando una descripción gráfica de los propietarios, sus trabajadores, sus posesiones materiales, sus tierras de cultivo, su entorno, etc. Al mismo tiempo, ayudan a enfatizar las relaciones sociales entre la clase acomodada y terrateniente y las clases más bajas que trabajaban para los miembros de las primeras ${ }^{46}$. A pesar de ello, destaca la capacidad del notario para plasmar al mismo tiempo la ostentación de una familia poderosa frente a la dura realidad de las familias trabajadoras de los jornaleros y del servicio de la casa, siempre con una mirada amable y cercana.

En definitiva, no cabe duda de que toda su obra fotográfica desarrollada en el territorio riojano posee una importancia capital desde diferentes puntos de vista, entre los que destacan los anteriormente comentados. Por consiguiente, todas las imágenes capturadas por Santos Fernández Santos en esta región, tanto las que aparecen en este trabajo como las que no han sido abordadas o se desconocen, merecen ser incluidas dentro del patrimonio fotográfico riojano permitiendo su estudio, su difusión, su conservación y su puesta en valor como lo que son, documentos fundamentales para el análisis de la evolución de la sociedad, el territorio y el patrimonio riojano durante las últimas décadas del siglo XIX y primeros años del siglo XX y como testimonios innegables de nuestra memoria colectiva.

46. En este sentido Luis Vicente Elías, en su capítulo "Fotografía y etnografía" en ROCAN DIO, Jesús, Cien años de fotografía en La Rioja. Logroño, Cultural Rioja, 1992, pp. 48 51, señala la precaución de utilizar las fotografías antiguas como documentos etnográficos pues, en muchos casos, buscaron retratar lo más tradicional y lo más chocante de los lugares fotografia dos. Sin embargo, este no parece ser el caso del reportaje de Santos Fernández Santos en la Hacienda de Somalo. 